\title{
Health Promotion and Life Course Dynamics: Transitions of Brazilian Elderly
}

\author{
Célia Pereira Caldas ${ }^{1 *}$, Carina Berterö ${ }^{2}$ \\ ${ }^{1}$ Nursing Faculty, Rio de Janeiro State University, Rio de Janeiro, Brazil \\ ${ }^{2}$ Department of Medical and Health Sciences, Division of Nursing Science, Faculty of Health Sciences, Linköping \\ University, Linköping, Sweden \\ Email: celpcaldas@hotmail.com, carina.bertero@liu.se
}

Received 22 January 2014; revised 28 February 2014; accepted 8 March 2014

Copyright (C) 2014 by authors and Scientific Research Publishing Inc.

This work is licensed under the Creative Commons Attribution International License (CC BY). http://creativecommons.org/licenses/by/4.0/

(c) (i) Open Access

\begin{abstract}
Background: Understanding life transitions is important to help people to achieve their developmental needs. No studies have examined the patterns of responses to life transitions, eliciting the experiences of growing old of retired Brazilian older adults. Aim: To identify and describe the patterns of responses to life transitions of retired Brazilian older adults. Design: Using a theoretical perspective of transition as a guide, a qualitative, secondary narrative research design was incorporated to obtain data from 11 interviews. Method: Initial data collection took place during a broader study on the influence of people's working life history. Eleven autonomous and independent persons, 64 - 82 years old, were interviewed at a geriatric outpatient unit in Rio de Janeiro to obtain their perceptions of old age. The secondary, narrative holistic-content analysis focused on the patterns of responses to life transitions. Results: The first turning point was a childhood event and the next was their first job. The third turning point was moving to another place/house or another city, the fourth starting a family, and retirement was the last turning point. Conclusions: While older people may feel environmentally disconnected throughout life, their patterns of response, together with the available resources and prevention/interventions influence the transition process. Health Promotion actions are needed at vulnerable points during the transition process, thereby facilitating the health outcomes.
\end{abstract}

\section{Keywords}

Transitions; Life Course; Health Promotion; Elderly Health; Brazil

\section{Introduction}

Older people’s daily lives, environments, and interactions are shaped by their living conditions and their experi-

*Corresponding author. 
ences of transitions. Transition patterns are shaped in the face of socioeconomic challenges. Transitions are both a result of and result in changes in lives, health, relationships, and environments [1]. The present study works with life histories of Brazilian seniors who grew old years before Brazil gained improvements in socioeconomic conditions.

Growing old is a life span transition. Retirement is a social and cultural transition. Both transitions may make older persons vulnerable. Aging and growing old is a very subjective experience. Older persons experience aging as occurring later; they postpone it. Being in need of care is something that others will experience, not the old persons themselves [2]. Nowadays, retiring from work life cannot be considered the only indicator of the transition into old age, especially not in the Western world. Transition into old age seems to be about habitation; to take care of oneself and live independently as long as possible [3]. Managing oneself could be about household downsizing in later life. Downsizing evokes a powerful sense of multiple timelines and is a transition that involves personal, family, social and cultural life [4].

Understanding life transitions is important to help people to achieve their developmental needs. In examining transition experience, it may be useful for Health Promotion professionals to consider a client's ability to deal with change and differences. The aim of this study is to identify and describe the patterns of responses to life transitions of Brazilian retired older adults, eliciting their experiences of growing old. The study spanned the period between the working life, retirement and old age.

\section{Transitions}

This study was framed by a nursing theory called the Transitions Theory [1]. As the foundation of this theory, Meleis defined the goal of healthy transitions as mastering behaviors, sentiments, cues, and symbols associated with new roles. The components of this theoretical framework are: types and patterns of transitions; properties of transition experiences; transition conditions: facilitators and inhibitors; patterns of response (process indicators and outcome indicators) and therapeutics. This study analysed each component, and the component "patterns of response” emerged as an important result.

Our review of the literature did not uncover any studies that specifically examined the patterns of responses to life transitions, eliciting the experiences of growing old, spanning the time period between the working life, retirement and old age in Brazil. Therefore, the research question posed was: What were the patterns of responses to the transitions?

\section{Method}

Secondary analysis of existing qualitative research data can be a valuable resource. It provides opportunities to bring a new perspective to bear on existing data or to use elements of the data that have not been fully analysed, or it can form the basis for comparison with newly collected data. Yet, the fit between available data and the "new research question" is an important issue to resolve [5]. Secondary analysis of qualitative data means returning to a data set that was collected for one set of purposes, to re-examine it with a slightly different set of objectives or to look at it from a different theoretical perspective [6]. For this study a secondary analysis of the qualitative data was determined to be the most effective approach to meet the study's goal. The theoretical perspective of Meleis' transition theory was the frame used to identify the patterns of responses to life transitions experienced by the persons under study in order to gain a deeper understanding of their transitions and the outcomes of these transitions. The research question in the present study fitted well with that of the original study. Approval from the Committee on Research Ethics was obtained.

In the previous study [7], eleven autonomous and independent persons, 64 - 82 years old, who were living in their own homes, agreed to participate in the study. Qualitative interviews were conducted at a geriatric outpatient unit at Rio de Janeiro State University. After obtaining informed consent, the interviews were tape-recorded and transcribed verbatim. The informants were three women and eight men. Information about the interviewees' social and demographic characteristics is given in Table 1.

\section{The Data Analysis}

The analysis was based on transcribed audiotaped interviews in Brazilian Portuguese. When qualitative research involves data in a language other than that in which it was collected, some particular considerations must be taken in account. The present study considered established guidelines for evaluating cross-language research [8]. 
Table 1. Interviewee’s social and demographic characteristics.

\begin{tabular}{cccccccc}
\hline Interviewee & Sex & Age & Main Working activity & Educational level & Civil state & Income situation & Lives with \\
\hline 1 & M & 68 & Dockworker & Elementary school & Married & Retired & Children and wife \\
2 & M & 66 & Clerk & Elementary school & Married & Retired & Children and wife \\
3 & M & 74 & Military & Elementary school & Married & Retired & Spouse \\
4 & M & 66 & Road Surveyor & Elementary school & Married & Retired & Spouse \\
5 & M & 71 & Farmer’s Market Vendor & Illiterate & Married & Retired & Spouse \\
6 & F & 64 & Maid & Illiterate & Married & Husband & Spouse \\
7 & M & 71 & Bus driver & High school & Married & Retired & Spouse \\
8 & F & 82 & Truck driver & Elementary school & Widow & Pension & Daughter and grandchildren \\
9 & M & 80 & Farm Worker & Illiterate & Widower & Retired & Alone \\
10 & F & 73 & Fabric Worker & Elementary school & Single & Retired & Sisters \\
11 & M & 64 & Messenger & Elementary school & Widower & Salary & Children \\
\hline
\end{tabular}

The same interpreter who conducted the interviews completed the transcriptions. The analysis was conducted in the language of the participants (Portuguese). The first author conducted all the interviews and translated them into English, enabling the other researcher to participate in the analysis.

In order to authenticate the translation, the Brazilian author conducted an analysis in English, based on the Portuguese transcription. The Swedish conducted another analysis based on the English translation. The Brazilian and the Swedish authors then compared their analyses, discarding the points where agreement was not reached. In this way, the findings were validated and the nuances in the language were preserved [9].

The transcripts were analysed and interpreted using narrative research from a holistic-content perspective [10]. Narrative research refers to any study that uses or analyses narrative materials, such as life stories. Holistic analysis of form is a narrative approach for learning about variations in structure. The formal aspects of structure, as much as content, express the identity, perceptions, and values of the storyteller. Analysing the structure of a story will therefore reveal the individual's personal construction of his or her evolving life experience. Progression of the narrative refers to the development of the plot over time [10].

The framework of transition articulated by Meleis et al. [11] was used to guide the analysis (types and patterns of transitions; properties of transition experiences; transition conditions: facilitators and inhibitors), resulting in identification of the "patterns of response". This content, as defined by Meleis, was marked with different colors and monitored throughout the story. For example, when reading one narrative, if a pattern of transition was identified, it was marked with blue, when a property of the same transition experience was later identified, it was marked in purple, and so on.

Meleis et al. state that the nature of transition includes the type of transition involved, such as developmental or situational. Following this distinction, the analysis started with the identification of type-situational or developmental. From that the different patterns of response emerged, with their properties and conditions (facilitators and inhibitors).

For Meleis, developmental transitions involve many changes in roles found in the normal path of human growth and development, which means that there is a wide variety of events that can trigger a transition. Situational transitions involve the addition or subtraction of people in an aggregate of pre-existing and complementary roles.

\section{Results}

The patterns of responses to life transitions regarding the experience of growing old for retired Brazilian older adults, spanning the period between the working life, retirement and old age, were found to be structured around five turning points. The first turning point was an event in childhood. The next turning point was the first job. The third turning point was moving to another place/house or another city. Starting a family was the fourth 
turning point and retirement was the last turning point. All these turning points could be applied to either situational or developmental transitions, but retirement was both. The results are illustrated in Figure 1.

\subsection{An Event in Childhood}

Only two of the narrators did not mention much about their family or childhood. Regarding the other nine, one had left home to live with another family and for eight of the narrators one of the parents had passed away.

Looking at the living conditions, the narrators expressed that what happened in childhood affected their entire life. As one narrator stated: "Then my dad died and I had to work, and never stopped working until today." Another condition was that several of the narrators had many siblings and had to earn money to support the family. Some of the narrators also had to move out of the family home, working as a domestic employee.

Although the narrators had a turning point early in life, they reflected that there were possibilities to have a better life after this turning point: "When I grew up, I managed to have a better life, no doubt about it. Let's put it this way: a 180-degree turn".

The narrators were mainly involved in the process of surviving and supporting or helping the family in many ways. This engagement in family survival forced most of them to disengage from school, but there was an awareness of the need for knowledge and creating possibilities, as in the following example: "I only completed the basic studies after I left the army. So I began working during the day and studying by night."

The narrators made it clear that they had to assume an adult role very early and all of them were proud of having "opened their way", as expressed by one of them. The most important outcome of parents passing away was feeling how hard life can be, as expressed by one interviewee: "So, life was very hard for me, because I had to work".

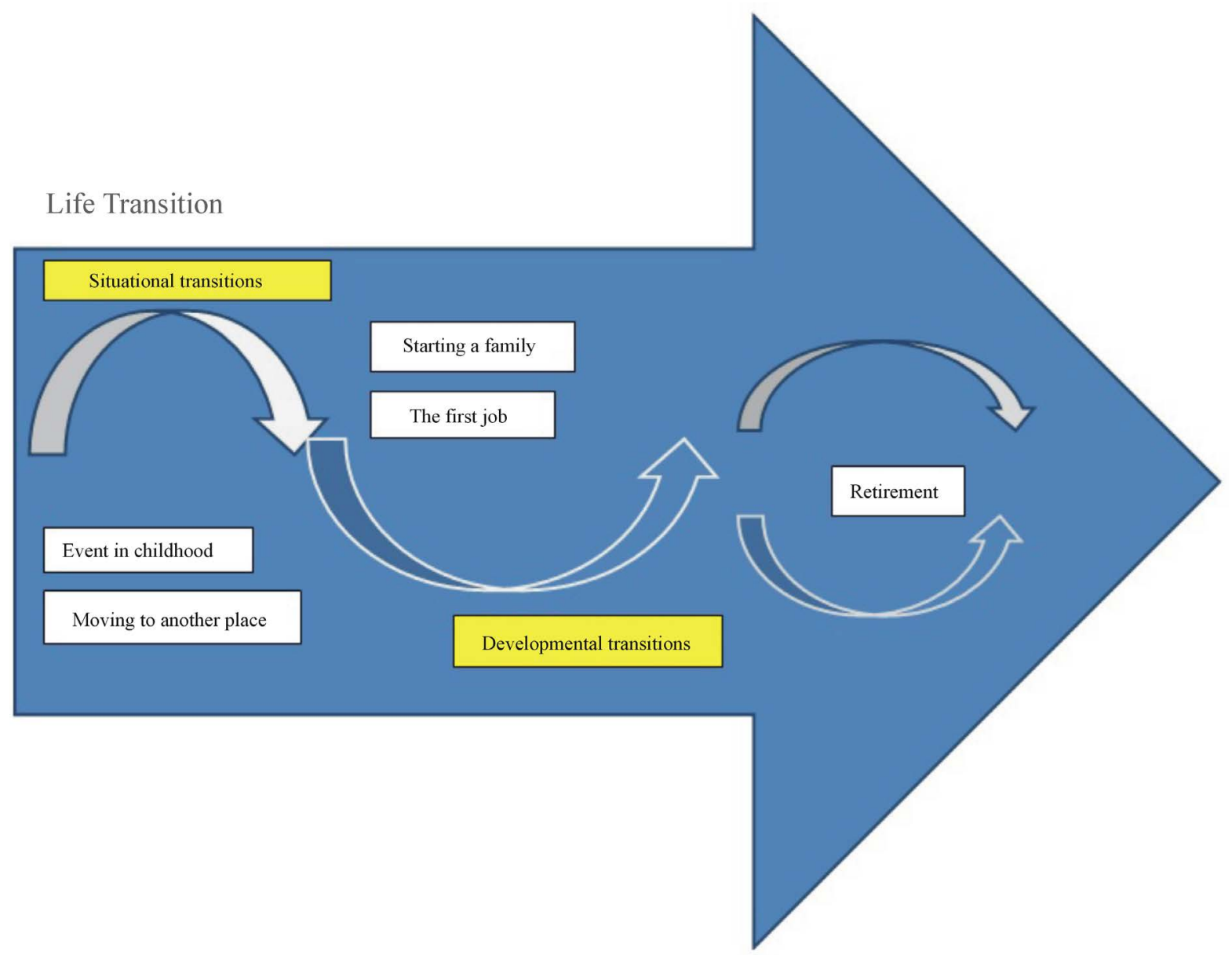

Figure 1. Turning points during life transition applied in situational and developmental transitions. 


\subsection{The First Job}

The narrators who in childhood lost a parent started to work at an early age. One of them stayed and worked for his father for 20 years without any salary. He got his first paid job at the age of 32. Only two of the narrators started working as adults.

Being a child worker meant being treated as a minor regarding decisions and payment, yet responsible for doing the work. As one narrator expressed it: "One day I waited for payment time. Everybody got their payment. The boss asked me what I was waiting for and I said I was waiting for the payment. No, you have nothing to receive. How come? Your father has already taken it. I arrived home and told my mom that my father had taken the money."

Talking about conditions in childhood and later on, some narrators were proud that their socioeconomic conditions became better than their parents'; "My life since I started working there has become much better than my parents'."

The narrators' reflections about their first job focused on the fact that they could improve their earnings if there were possibilities to study or be educated. Being a worker engaging in the first job as well as the work that followed, was characterised by seeking information and learning-by-doing in order to perform new roles: "I began without knowing the job. I had to mix the cement. Then, as the mason, I bought a trowel and other things and, in my free time, I learned with the mason master.”

Engaging in working life led to seeking information and learning. Although almost all of the narrators changed jobs, they never let an opportunity go to learn something more, something new. Changing jobs was also a continuous process of engagement, learning, role shifts, and then, disengagement. The narrators became aware of the need to have certain skills in the working situation, which also gave confidence in life, such as the ability to manage different situations.

When survival was the only motivation, work became the denial of pleasure. Those who had a working life that was clearly understood as a struggle for survival also reported that it was not worth fighting for better working conditions. Therefore, they did not believe and did not participate in the union movement or in other political organizations defending the rights of workers. "If you do not work the boss will not pay you. If you strike, you will be affected, so if you do not have the strength to solve things, I think it is best not to strike.” The narrators presented reflections on the issue of not fighting for workers' rights, indicating that it was not worth the effort or was meaningless. Some of them expressed sentiments similar to this interviewee: "Better working conditions did not exist. I had to be satisfied! Everything depends on what you do, on your good will... This business of the workers' movement, it only harms the country and worries the population, which suffers during certain strikes and has nothing to do with it."

However, some subjects indicated that it was possible to resist oppression and fight. Two narrators showed the importance of organizing the labor force to demand their rights. There was also great solidarity among workers. This situation happened with subjects who had a sense of belonging to a social category. Some subjects were proud of belonging to organized groups of workers, which could improve their working conditions, as expressed by: "So, as I say, the docks are the best job in the world. Dockworkers are global, right? Dockworkers are well organized. We have a federation, we have the unions..."

The responses and outcomes were clearly different when the working conditions enabled personal development or sense of belonging. This applied to those whose work was linked with family, those engaged in worker's rights movements, those who expressed solidarity among their colleagues, feelings of belonging to a community, friendship, pleasure, comradeship. In these cases, the responses about aging were expressed as an inability to maintain the activities that had been most valued lifelong. Even so, those individuals showed as an outcome a strong ability to resist loss. The perceptions of usefulness and autonomy were outcomes more developed in this particular group of narrators than in the case of individuals who had established a unilateral relation of work-survival.

\subsection{Moving to Another Place/House or Another City}

Moving was connected to what happened in childhood but also to work opportunities. Although almost all narratives pointed out that moving was an important turning point; they did not express any reflexive thinking about it. They just stated that moving was important to get better working conditions, as expressed by: "He thought it would be better if I came to Rio, so I took the chance and came.” 
Moving was a turning point, but also a response. Moving was found to be a response to parents passing away and to changing jobs. Regret about moving was a frequent outcome in this group: "But so far I have regretted coming here. It disturbed my life; maybe I would have a degree in something if I had stayed in Santos.” Moving could be seen as an opportunity, and could open a way for something new and good. Moving could also be seen as something that hindered development and personal growth. In this response there was hope and a feeling of change for the better, but also regret about the response made. Hence, you can only regret things you did not do.

\subsection{Starting a Family}

Ten narrators were married. For the men, it was common to start a family between 22 and 37 years of age. The narrators stressed the need for stability and security not only for starting, but also for raising a family. This need guided all decisions they had to make through their lives until old age: "If I work, and fortunately have a salary, I can support my family, no matter what; if I don't work, no politician will give me money. No government will give me money, my family will starve, will be in need, and this is not useful to anyone.” The narrators all expressed the responsibility that comes with starting and raising a family. Some human needs require to be fulfilled.

They also expressed the awareness and reflexive thinking about the influence of starting a family for improving their quality of life: "Life improved a lot after I got married. Before, we were in need. I got wiser when I got married. Before, I even gambled, but I stopped. Now I do not work anymore, but my kids help me.” Having or being part of a family had a great impact on the narrators, since it placed them in a context where they were valued.

It was pointed out by the narrators that starting a family had as a response and outcome a shift in social activities and in the quality of life: “After I was married, when we went out, we visited relatives. Then the children came, sometimes we went to the zoo, or... these things that we do, parks... always some activity.”

\subsection{Retirement}

Retirement was an important turning point. Eight narrators were retired even though one still maintained one job to receive two incomes (job salary and pension). One narrator was still working and two women were not receiving pensions. It is also important to understand how the aging process influenced the work conditions. The narrators pointed out a progressive loss of respect in the relationship with the younger colleagues: "I had a good relationship with younger colleagues, but in the last five years in the company, from 1970 to 1978, some new employees appeared in the company that had no respect for the white hair or the knowledge of the older ones. They thought they should change everything the way they wanted and sometimes there were even arguments between the older ones and the younger ones because of the job, because they did not do the job with the same quality it was done before.” In some cases, the narrators showed that physical conditions related to the aging process determined changes in working conditions.

Some of them showed awareness of the importance of planning early for retirement: "I planned myself, for retirement... I earned less (as a retired person), but I was not bothered. I did not need to leave early for work and such. It was good for me, I had my savings to live on, I mean, I made a good deal retiring then...”

Some narrators did regret retiring. They missed working activities, as one narrator reflected, "I was silly to retire. I shouldn't have retired at the age I did. I retired when I was 50 years old, with 36 years of work and, at first, my situation was pretty much the same.” Others showed awareness about the loss of physical health being one of the causes for retirement. They reflected about being able to continue working, but this "senior work" should be adapted to their actual conditions, and they could advise young workers. "I think the older workers could explain, guide, do a bunch of things for the young people, but I don't know anyone who wanted this guidance, who would ask me something.”

Retiring itself was a response, mainly to prejudice against older workers, as expressed by: "In some of the cases, even my superior was prejudiced against the older people, including me... I didn't argue with him or anything, but this was an important reason behind my requesting retirement.” Not being seen or respected as the senior person they are could lead to the response of retirement. Another response to retirement was expressed as: "Now I live a retired life. I like to walk... I go to a shop, a fair, go inside to chat, and I know the price of things...." On the other hand, there was a shift in social activities as an outcome. There were no workmates to spend time with and talk to after work. This daily relationship with friends/workmates was not there and they 
stayed at home more. Some narrators had a completely different response and maintained the friendship with colleagues: "After I stopped working, I kept my friends. My colleagues, we were very close, and we have continued like this, being friends. They visit me and I visit them."

The narrators said they engaged in reflexive thinking about old age. They pointed out the importance of being psychologically prepared, and their awareness of physical insufficiency. Some men expressed a preoccupation with sexual performance and sexuality. Women reflected upon the changes in the household: "The work of the household changes a lot when you are old. It changes because one can't climb a ladder, wax the floor, can't work for anyone to help a little, and can't clean someone's house.”

All narrators recognized that they had gained at least some wisdom from their life experiences: "Well, of course, as we age, the head gets a little rest and then we are not so... we don't pick fights so often as before; nowadays things are not what is right, what is wrong... But we have wisdom, there it is: we acquire more wisdom." Nevertheless, they were aware that wisdom was not always valued. Some narrators said that the younger generation did not have the spirit they had, "even with older flesh", but wisdom was not valued and the attitude was that there was no hope in old age.

For this group of older people, engaging in old age meant to assume roles mainly related to housework, health care, or self-care: "Today my activity is... Grab a brush, paint the house, do some plumbing, some electrical job, I know a little bit about everything. Therefore, my activity is constant. I do not stop. And if I stop I rest, I take care of myself. That is why, despite my age, I still think I am able to do anything."

Old age was identified as a withdrawal from society, as a response. Those who presented this response also showed their awareness of the progressive loss of older people's acceptance by society. Loneliness was the main outcome of this response. For example, this group gave the following statements: "To be old is sad, really sad. To be old is to be self-conditioned to accept everything from others. The older person doesn't have any way to resist."

On the other hand, some narrators expressed positive responses and consequential positive outcomes to old age. The narrators reacted to the losses and found as a result social inclusion: "Today I do not consider myself old, because I wash, iron clothes, cook, wax the house. I have my activities, I go to the movies, take saunas, I jump rope, ride a bike... Old age, for now, is not a burden.” A response to old age was being aware of biological and physical changes and limitations, but continuing life as normal even though some adaptations were made in activities and performance.

\section{Discussion}

The purpose of this study was to identify and describe the patterns of responses to life transitions of retired older adults because understanding life transitions is important to help people through Health Promotion actions and to achieve their developmental needs.

Transition is a natural process associated with changes in our lives, such as aging, changing relationships and changes in health status [11]. When looking at transition there is always a beginning. In our interviews, everything started with an event in childhood. The first turning point, an event in childhood, was a situational transition. There were certain circumstances that affected the interviewees' lives and that forced them to change, for instance, to start working early to help to support their family, to finish school or to move to another place/home [12].

Moving on from this childhood event, which in some cases could be seen as disconnection with childhood, people arrived at the second turning point; the first job, which was a developmental transition. In the same way, moving to another place/house or another city was a situational transition, and starting a family was another developmental transition.

There is always something before, or something that becomes the starting point for a trajectory. Bridges [13] states "every transition begins with an ending", meaning that people have to redefine themselves. Transition could be seen as a process of change in life's developmental stages or alterations in health and social circumstances, but it also includes people's responses to change. Transition is the movement and adaptation to change, rather than a return to a pre-existing state.

Regarding retirement, some factors must be taken into consideration. Not all the interviewees attributed to this turning point the meaning of being engaged in old age. Some people who consciously engaged in old age showed positive responses to that and others showed negative responses. In fact, engaging in old age was not 
identified as a turning point. On the other hand, retirement clearly emerged as a turning point. For some interviewees, retirement was a situational transition. Nevertheless, for others, it was a developmental transition. For those who were adapting, maintaining connections and life goals, and who were aware of the limitations old age brought, retirement was a developmental transition.

Looking to each turning point and at the periods between them, it was possible to understand that the turning point occurs when the present reality no longer works. In that sense, the first job marked the transition from childhood/adolescence to adulthood. The transition was also from the familiar cultural environment to a broader social environment. This kind of cultural change also occurs when the individual experiences the transition of moving to another place/house or another city. Therefore, those transitions were characterized by cultural adjustment. Community support, socioeconomic status, and knowledge were conditions that facilitate cultural adjustment, but the transition of "moving to another place" was hindered when it separated the person from family and friends. These conditions were in agreement with what Chang et al. [14] pointed out, namely that ego-integrity in late adulthood is closely related to cultural and psycho-social environmental influences throughout the life span. Culturally sensitive approaches are important when intervening in the specific ways that older adults achieve their own ego-integrity throughout their life experiences. Growing old and perhaps becoming frail is a transition that, according to Nicholson et al. [15], is affected by the presence of others; people who will engage with them and value their daily rituals, helping them retain their quality of life and capacity to enjoy it whilst being frail.

The interviewee's life transitions were made in the face of socioeconomic challenges. Regarding the fact of working with a secondary analysis, it can be argued that Brazil's socioeconomic conditions improved after this study's participants grew old and because of that, the results would be different if the interviews were made nowadays with people the same age as the interviewees. Nevertheless, it should be considered that the improvements were not so dramatic that they would produce different results.

The authors acknowledge that using translated data was a limitation of the study and may threaten the trustworthiness of the results. Even though data analysis took place in two languages, conceptual equivalence issues may have occurred during the analysis and translation processes. In order to control for possible translation errors, the researchers compared their analyses to evaluate the confirmability and trustworthiness of the results [8] [16]. But as Temple [17] states, when the language used in interviews is not that of the written transcripts, researchers have a responsibility to investigate how they are representing people in the translation process. This issue is something we bore in mind all the time.

\section{Conclusion and Implications for Health Promotion Practice}

The response patterns, available resources and prevention/intervention all influence the transition process. According to the Transitions Theoretical perspective, the goal of Health Promotion should be to empower individuals at vulnerable points during the transition process, facilitating health outcomes. Many older people feel environmentally disconnected throughout life. Environment and social disconnectedness are vulnerabilities that can be addressed by health care providers during the life course and with people of all ages, particularly with frail older persons. Transitions are also from a familiar cultural environment to a broader social environment, and therefore they are characterized as cultural adjustments. Community support, socioeconomic status and knowledge are conditions that facilitate cultural adjustment. This knowledge is important to inform Health Promotion practice, particularly when working with Brazilian older persons living abroad.

\section{References}

[1] Meleis, A.I., Sawyer, L.M., Im, E.O., Messias, D.K. and Schumacher, K. (2000) Experiencing Transitions: An Emerging Middle-Range Theory. Advances in Health Promotion Science, 23, 12-28.

[2] Graefe, S., Van Dyk, S. and Lessenich, S. (2011) Altsein ist Später. Zeitschrift für Gerontologie und Geriatrie, 5, 299-305. http://dx.doi.org/10.1007/s00391-011-0190-5

[3] Hochheim, E. and Otto, U. (2011) Das Erstrebenswerteste ist, dass man sich so lange wie möglich selbst versorgt. Zeitschrift für Gerontologie und Geriatrie, 5, 306-312. http://dx.doi.org/10.1007/s00391-011-0191-4

[4] Uborsky, M.R., Lysack, C.L. and Van Nuil, J. (2011) Refashioning One’s Place in Time: Stories of Household Downsizing in Later Life. Journal of Aging Studies, 25, 243-252. http://dx.doi.org/10.1016/j.jaging.2011.03.009 
[5] Heaton, J. (2004) Reworking Qualitative Data. Sage Publications Ltd., London.

[6] Ritchie, J. and Lewis, J. (2003) Qualitative Research Practice. Sage Publications, London.

[7] Caldas C.P. (1997) Memória, Trabalho e Velhice: Um Estudo das Memórias de Velhos Trabalhadores. In: Veras, R.P., Ed., Terceira Idade: Desafios para o Terceiro Milenio, Relume-Dumará, Rio de Janeiro, 121-142.

[8] Squires, A. (2008) Language Barriers and Qualitative Health Promotion Research: Methodological Considerations. International Health Promotion Review, 55, 265-273.

[9] Arizcum, M.A. (2011) The Right Message. Seprotec. http://www.seprotec.com/index.php?option=com docman\&task=doc view\&gid=99\&Itemid

[10] Lieblich, A., Tuval-Mashiach, R. and Zilber, T. (1998) Narrative Research: Reading, Analysis and Interpretation. Applied Social Research Methods. Sage Publications, Thousand Oaks.

[11] Meleis, A.I. (2010) Transitions Theory. Springer Publishing, New York.

[12] Godfrey, M. and Townsend, J. (2008) Older People in Transition from Illness to Health: Trajectories of Recovery. Qualitative Health Research, 18, 939-951.

[13] Bridges, W. (2004) Transitions: Making Sense of Life’s Changes. Da Capo Press, Cambridge.

[14] Chang, S.O., Kim, J.H., Kong, E.S., Kim, C.G., Ahn, S.Y. and Cho, N.O. (2008) Exploring Ego-Integrity in Old Adults: A Q-Methodology Study. International Journal of Health Promotion Studies, 45, 246-256.

[15] Nicholson, C., Meyer, J., Flatley, M. and Holman C. (2012) The Experience of Living at Home with Frailty in Old Age: A Psychosocial Qualitative Study. International Journal of Health Promotion Studies, 50, 1172-1179.

[16] Squires, A. (2009) Methodological Challenges in Cross-Language Qualitative Research: A Research Review. International Journal of Health Promotion Studies, 46, 277-287.

[17] Temple, B. (2008) Narrative Analysis of Written Texts: Reflexivity in Cross Language Research. Qualitative Research, 8, 355-365. http://dx.doi.org/10.1177/1468794106093632 